\title{
Thermodynamic and thermoeconomic analysis of combined geothermal space heating and thermal storage using phase change materials
}

\author{
V. Chauhan ${ }^{1,3}$ and Á. Ragnarsson ${ }^{2}$ \\ ${ }^{1}$ Reykjavik University, Reykjavik, Iceland \\ ${ }^{2}$ IcelandGeoSurvey (ISOR), Reykjavik, Iceland \\ ${ }^{3}$ UNU Geothermal Training Programme, Reykjavík, Iceland \\ Correspondence to: V. Chauhan (vijay30008@gmail.com)
}

Received: 2 June 2015 - Revised: 3 August 2015 - Accepted: 24 September 2015 - Published: 10 December 2015

\begin{abstract}
The present work discusses the utilization of phase change materials for energy storage in geothermal space heating systems. Thermodynamics and thermoeconomics of the combined heating and thermal storing system were studied to show the scope of energy storage and cost savings. A computational model of the combined space heating and thermal storage system was developed and used to perform thermodynamic studies of the heat storage process and heating system efficiency at different times and ambient temperatures. The basis for these studies is daily variations in heating demand that is higher during the night than during the day. The results show the scope of the utilization of phase change material for low ambient temperature conditions. Under proper conditions a sufficient amount of exergy is stored during the charging period at a low ambient temperature to fulfill the daytime heat load requirement. Under these conditions the cost flow rate of exergy storage is found to be lower than the radiator heating cost flow rate. Thus, the use of exergy storage at low ambient temperatures for heating at higher ambient temperatures makes a significant contribution to cost savings.
\end{abstract}

\section{Introduction}

Space heating has been one of the most well-known applications of geothermal energy utilization for decades. The use of geothermal energy for space heating provides an economical and a non-polluting method for achieving human comfort. In order to study a thermodynamic system's performance that can either involve heating or power generation, the second law of thermodynamics plays an important role. The second law helps to better understand energy flow processes alongside the first law of thermodynamics. Exergy is the maximum theoretical useful work obtainable as the systems interact to equilibrium, the heat transfer occurring with the environment only. Several studies have been conducted on the exergy analysis of buildings. The concept of low exergy systems for heating and cooling was proposed in Annex 37 (2000). An exergetic life cycle assessment for resource evaluation in the built environment was conducted by Meester et al. (2009). Shukuya and Komuro (1996) applied concepts of entropy and exergy for investigating the relationships between buildings, passive solar heating, and the environment. Various results about patterns of human exergy consumption in relation to various heating and cooling systems were given by Saito and Sukaya (2001). Conclusions were made about the inadequacy of the energy conservation concept for understanding important aspects of energy utilization processes by Yildiz and Gungör (2009). The second-law analysis is important for an efficient utilization of the available resources.

\subsection{Phase change material}

One of the best solutions for the problem when supply and demand are out of phase is the use of energy storage materials. The key to the effective utilization of renewable energy sources is efficient and economical energy storage systems. One of the most efficient ways of storing heat is the application of phase change materials (PCM). Such systems absorb and release heat energy as latent heat of the storing material 
with a change of phase. Various advantages of the application of PCM over other storage systems have helped the method to gain importance over the years. The study done by Adebiyi and Russell (1987) concluded two advantages derived from using a phase change material in a thermal energy storage system design. The first advantage was the increase in second-law efficiency of the system as compared to systems that use sensible heat storage. The second major advantage was concluded to be the reduced amount of storage material required. Since PCM is based on the principle of storing heat as latent energy of phase change, the energy stored is far higher than that stored by sensible heating systems that store energy equal to their specific heat capacity.

Various analyses of the latent heat storage based on the first law of thermodynamics can be found in various literature. The first-law analysis helps us to obtain a workable design but not an optimum one. In order to consider the effect of time and the temperature at which heat is supplied, secondlaw analysis is required. According to Bejan et al. (1996) an optimal system which a designer can develop with the least irreversibility is based on the minimization of entropy generation. The application of second-law analysis for studying latent heat storage was studied by Bjurstrom and Carlsson (1985) and Adebiyi and Russell (1987), and was later added to by Bejan (1996). A study was done by El-Dessouky and Al-Juwayhel (1997) which investigated the effect of different variables on the entropy generation number defined by Bejan et al. (1996). The analysis considered the case of the storage material exchanging heat at a constant melting point. For analysis, two commonly available storing materials, paraffin wax and calcium chloride, were considered, with air or water as the heating fluid.

A number of materials exist which can be used as PCM over a wide range of temperatures. A list of such materials can be found in the literature (Abhat, 1983). The selection of a PCM for energy storage is based on the fulfillment of criteria such as high latent heat capacity, non-corrosiveness and high thermal conductivity; and it should be non-toxic without deposition or supercooling. The transition temperature of the phase change material is decided by the room temperature required.

\subsection{Importance of PCM for geothermal energy storage}

Studies on the analysis of PCM, both numerical and experimental, have been reported in the literature (Farid et al., 2004). The cited work is mainly focused on solar energy storage. It is important to be aware of the necessity of storing geothermal energy where the mass flow itself can be controlled. The answer to the question depends upon the conditions for storage application. For an existing heating system using radiators and heat exchangers, an important fact discussed in the literature (Karlsson and Ragnarsson, 1995) is the variation of geothermal exit temperature with outside ambient temperature for a fixed design network. It is found that as the ambient temperature decreases, the exit temperature of the geothermal heating network increases. The increase in exit temperature reflects an increase in useful heat loss. In terms of second-law efficiency, the decrease in ambient temperature causes an increase in exergy loss to the atmosphere. Surely the application of energy storage can provide a means of saving energy which can be used off-peak when the demand is low. Stored heat from the geothermal exit fluid at night can be used for fulfilling the daytime requirement. The other advantage of thermal storage for geothermal application is found in areas with limited flow and high heat demand. Heat energy in such cases can be stored during offpeak or daytime periods and can be utilized for peak load demands during the night. Managing the heating from limited flow will also help save drilling costs by reducing the need for new wells.

\subsection{Thermoeconomics}

Thermoeconomic or exergoeconomic analysis considers both thermodynamic and economic principles for improving systems' performance. Exergoeconomic analysis helps in quantifying the exergy losses in terms of monetary losses. According to Bejan et al. (1996) exergoeconomics is defined as the branch of engineering that combines exergy analysis and economic principles to provide the system designer or operator with information that is not available through conventional energy analysis and economic evaluations, yet is crucial to the design and operation of a cost-effective system. Application of exergoeconomic analysis can be found in the literature for processes involving heat transfer and power generation. Exergetic cost analysis for space heating using a ground source heat pump system was done by Jingyana et al. (2010). The work shows the sensitivity of various subsystems to unit exergy cost. The application of exergoeconomic analysis to a geothermal district heating system was presented by Oktay and Dincer (2009) and reviewed by Hepbasli (2010) using energy, exergy, and economic aspects. Performance evaluation of the geothermal heating system and case studies were conducted by Kecebas (2011). The effect of reference temperature on the thermoeconomic evaluation of geothermal heating systems was studied by Kecebas (2013).

In this context the current work proposes the use of phase change material for geothermal energy storage combined with a radiator heating system. Thermodynamic and thermoeconomic aspects of the proposed system are studied, taking second-law efficiency of the system into consideration.

\section{Thermodynamic modelling}

Figure 1 shows the schematic diagram of the combined space heating and thermal storage system. The geothermal water is first passed through a heat exchanger, passing heat to the secondary fluid. The secondary fluid passes through the radiator heating system, transferring heat to the room, and 


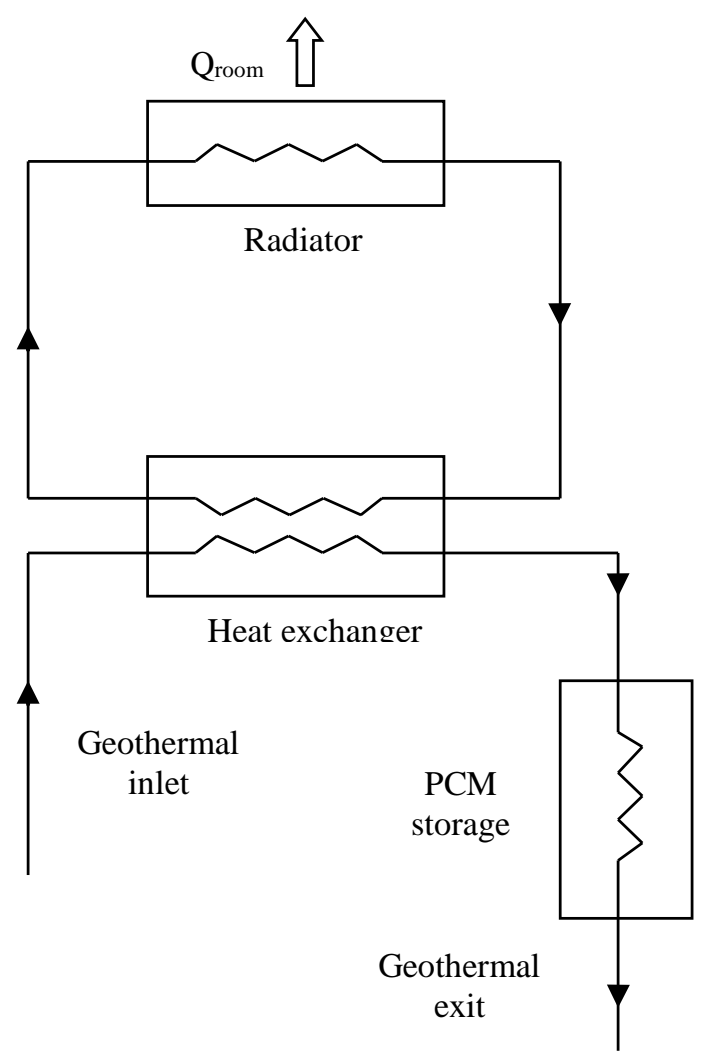

Figure 1. Schematic diagram of combined heating and storing system.

then returns back to the heat exchanger, forming a closed loop. The geothermal fluid, after exiting the heat exchanger, passes through the phase change thermal storage system. The geothermal fluid passes heat to the phase change material and then exits out of the system. Thermodynamic modelling of the combined system is described below.

\subsection{Heating system}

The current analysis assumes the use of an indirect method of space heating with radiators and plate-type heat exchangers as mentioned in Karlsson and Ragnarsson (1995). The geothermal fluid transfers heat to the secondary fluid which is passed through the radiators for room heating. The radiators manufactured are designed for fixed design conditions at the assumed room temperature. For temperatures other than the design temperature, the heat load is calculated as

$\dot{Q}_{T}=\dot{Q}_{\mathrm{des}}\left(\frac{T_{\mathrm{amb}}-T_{\mathrm{room}}}{T_{\mathrm{des}}-T_{\mathrm{room}}}\right)$.

The value of logarithmic mean temperature difference (LMTD) between the radiator and the room under design conditions is given as

$\mathrm{LMTD}_{\mathrm{R}}=\frac{T_{\mathrm{R}, \text { in }}-T_{\mathrm{R}, \text { out }}}{\ln \left(\frac{T_{\mathrm{R}, \text { in }}-T_{\text {room }}}{T_{\mathrm{R}, \text { out }}-T_{\text {room }}}\right)}$.
Knowing the logarithmic mean temperature difference for the design conditions, the logarithmic temperature difference at different conditions is calculated as

$\frac{\dot{Q}_{T}}{\dot{Q}_{\mathrm{des}}}=\left(\frac{\mathrm{LMTD}_{\mathrm{R}}}{\mathrm{LMTD}_{\mathrm{R}, \mathrm{des}}}\right)^{n}$.

The value of the exponent $n$ is 1.3 (Anon, 1977).

On obtaining the logarithmic mean temperature difference, the value of the radiator outlet temperature can be calculated using Eq. (2).

Obtaining the temperature at the radiator outlet, the mass flow rate of fluid required through the radiator is found using the equation given below:

$\dot{m}=\frac{\dot{Q}_{T}}{C\left(T_{\text {in }}-T_{\text {out }}\right)}$.

Calculation of the above parameters for the radiators allow us to be able to fully describe the radiator or secondary fluid side of the system. The output parameters from the radiators as well as the geothermal fluid inlet temperature are input parameters for the heat exchanger. In general, plate-type heat exchangers are used for residential heating due to their advantages of compactness, high heat transfer rate, and ease of construction and maintenance over shell- and tube-type heat exchangers. For calculation of heat transfer coefficients through plate heat exchangers, the current analysis uses the relation suggested by Incropera et al. (2007) for flow through circular pipes with a diameter equal to the hydraulic diameter of a non-circular channel of the heat exchanger, through which the geothermal and the secondary fluids pass. The relation is given as

$\mathrm{Nu}=0.0296 \operatorname{Re}^{0.8} \operatorname{Pr}^{0.333}$.

Calculating the convective heat transfer coefficient for both radiator side and geothermal side fluid, the overall heat transfer coefficient can be determined.

The amount of heat transferred through the heat exchanger is then given as

$\dot{Q_{T}}=A_{\mathrm{HX}} \cdot U_{\mathrm{HX}} \cdot \mathrm{LMTD}_{\mathrm{HX}}$.

Knowing the value of heat exchange required and the area of the heat exchanger selected for the specific design, the logarithmic mean temperature difference of the heat exchanger can be calculated from the above equation. The geothermal exit temperature from the heat exchanger can then be calculated from the following equation:

$\mathrm{LMTD}_{\mathrm{HX}}=\frac{\left(T_{\text {geo,in }}-T_{\mathrm{R}, \text { in }}\right)-\left(T_{\text {geo,out }}-T_{\mathrm{R}, \text { out }}\right)}{\ln \left(\frac{T_{\text {geo, in }}-T_{\mathrm{R}, \text { in }}}{T_{\text {geout }}-T_{\mathrm{R}, \text { out }}}\right)}$.

Knowing the return water temperature from the above equation, the mass flow rate of geothermal fluid can be found using Eq. (4). 


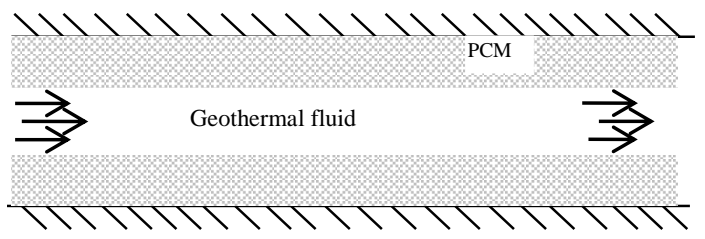

Figure 2. Configuration of storage system.

\subsection{Phase change material}

The current work focuses on the analysis of PCM combined with a geothermal space heating system, taking fixed values of design parameters such as storage component length, diameters, and mass of phase change material. The aim of the study is to calculate the amount of energy and exergy saved using PCM combined with geothermal space heating. The mass of phase change material was assumed to be $400 \mathrm{~kg}$. The mass of the storage material and other physical properties was kept constant during the analysis. The heat storage system has two concentric cylinders with inner and outer diameters of 0.02 and $0.045 \mathrm{~m}$ respectively. The heat source fluid flows through the inner cylinder and the storage material is filled in the annulus between the cylinders, as shown in Fig. 2.

The small outer diameter of the cylinders allows such an arrangement to be laid along the floor or walls of a room in a loop, similar to a radiator floor heating arrangement. The parameters such as diameters, length, and phase change material weight can have optimized values as per the room dimensions and heat load. It is to be made clear that the analysis does not claim the current cylindrical arrangement of storage system as the optimum arrangement. The PCM material used is calcium chloride. The properties of the PCM material and the heating fluid (water) are taken from El-Dessouky and AlJuwayhel (1997). Analysis for the PCM using air and water as heating fluid was discussed in the corresponding literature that considered water and air as the ideal working fluid. For the calculation of exergy terms, this assumption is not fully validated for water. Exergy analysis for PCM was also done by Bjurstrom and Carlsson (1985). Relations were derived for the amount of exergy stored in the PCM and final temperature of the storage material. The current work uses the equations derived by Bjurstrom and Carlsson (1985) for analysis of the storage system. The main assumptions used in the analysis are as follows.

- There is no heat exchange between the storage system and the surrounding area during the charging process.

- The heat exchanger wall is assumed to have no resistance to heat transfer.

- Thermophysical properties of the PCM and flowing fluid are assumed to be constant.
- Since the analysis is done using phase change material with a low transition temperature, the temperature difference between the transition temperature and room temperature is small; hence all stored exergy is assumed to be used for room heating.

- The heat transfer coefficient of the fluid (geothermal water) side $\left(h_{\mathrm{f}}\right)$ is calculated using Eq. (5), assuming flow through the cylinder to be turbulent.

The heat transfer coefficient between the wall and storage material is calculated according to the relationship developed by Yanadori and Masuda (1989) based on experimental data.

$h_{\mathrm{m}}=\frac{2 \lambda_{s}}{0.4\left(D_{\text {inner }} \ln \left(\frac{D_{\text {outer }}}{D_{\text {inner }}}\right)\right)}$

Calculating the convective heat transfer coefficient for the geothermal fluid and the phase change material side, the overall heat transfer coefficient for the PCM storage is calculated as

$\frac{1}{U_{s}}=\frac{1}{h_{\mathrm{f}}}+\frac{1}{h_{m}}$.

In the above equation, resistance due to the wall is neglected as it is small in comparison to the convective heat transfer coefficients.

The number of transfer units (NTU) on the fluid side is given by the following equation:

$\mathrm{NTU}=\frac{-U_{s} \pi D_{\mathrm{inner}} L_{s}}{\dot{m}_{\mathrm{geo}} c_{\mathrm{geo}, \mathrm{f}}}$

For the analysis the initial temperature of the storage material and inlet temperature of the heat source is assumed. The procedure used for calculation of the final storage temperature and the amount of stored exergy is found from equations given by Bjurstrom and Carlsson (1985). The procedure used is detailed as follows.

A dimensionless time $\Omega$ is defined as

$\Omega=\frac{\dot{m}_{\mathrm{geo}} c_{\mathrm{geo}, \mathrm{f}}}{M_{\mathrm{pcm}} C_{\mathrm{pcm}}} t$.

For the analysis, temperatures are made dimensionless using the following equation:

$\theta=\frac{T-T_{o}}{T_{o}}$,

where $T_{o}$ is the reference ambient temperature $(\mathrm{K})$.

The temperature efficiency $(r)$ of the heat exchanger is given as

$r=1-\exp (-\mathrm{NTU})$ 
For a stratified source with NTU on the fluid side, the relation can be approximated as

$r=\frac{\mathrm{NTU}}{1+\mathrm{NTU}}$.

Since the phase change materials exhibit three stages, absorbing sensible heat in solid phase from initial temperature to the transition stage, latent heat during the transition phase, and then sensible heat in the liquid phase, an equivalent heat capacity is defined by the relation:

$$
\begin{aligned}
& M_{s} C_{\mathrm{pcm}}\left(T_{l}-T_{b}\right) \\
= & M_{S} C_{s}\left(T_{m}-T_{b}\right)+M_{s} H+M_{s} C_{l}\left(T_{l}-T_{m}\right),
\end{aligned}
$$

or

$\theta_{l}-\theta_{b}=\alpha\left(\theta_{m}-\theta_{b}\right)+\omega\left(\theta_{l}-\theta_{b}\right)+\sigma\left(\theta_{l}-\theta_{m}\right)$.

The constants $\alpha, \omega$ and $\sigma$ are given as

$$
\begin{aligned}
\alpha & =\frac{C_{s}}{C_{\mathrm{pcm}}}, \\
\omega & =\frac{\Delta H}{C_{\mathrm{pcm}}\left(T_{l}-T_{b}\right)}, \\
\sigma & =\frac{C_{l}}{C_{\mathrm{pcm}}} .
\end{aligned}
$$

For heating at temperatures below the phase transition temperature, the instantaneous storage temperature as a function of time is given as

$\theta_{s}=\theta_{b}+\left(\theta_{i}-\theta_{b}\right)\left(1-\exp ^{-r \Omega^{\prime}}\right)$,

where $\Omega^{\prime}$ is given as

$\Omega^{\prime}=\frac{\Omega}{\alpha}$.

For heating the PCM above the transition temperature, the equation for instantaneous storage temperature and geothermal fluid outlet temperature is given as

$\theta_{s}=\theta_{m}+\left(\theta_{i}-\theta_{m}\right)\left(1-\exp ^{-r \Omega^{\prime \prime}}\right)$

$\theta_{e}=\theta_{i}(1-r)+\theta_{m} r$

where $\Omega^{\prime \prime}$ is given as

$\Omega^{\prime \prime}=\frac{1}{\sigma}\left(\theta-\left(\frac{\alpha}{r} \ln \left(\frac{\theta_{i}-\theta_{b}}{\theta_{i}-\theta_{m}}\right)\right)-\frac{\omega}{r}\left(\frac{\theta_{l}-\theta_{b}}{\theta_{i}-\theta_{m}}\right)\right)$,

where second and third terms in the brackets represent the dimensionless terms required for bringing PCM to the phase transition temperature and its completion.

For PCM where the storage temperature exceeds the transition temperature, the amount of energy stored in the PCM is given by

$$
\begin{aligned}
& Q_{\text {stored }} \\
& =M_{\mathrm{pcm}} C_{s}\left(\theta_{m}-\theta_{b}\right)+M_{\mathrm{pcm}} H+M_{\mathrm{pcm}} C_{l}\left(\theta_{s}-\theta_{m}\right) .
\end{aligned}
$$

\section{System analysis}

\subsection{Exergy analysis}

\subsubsection{Heating system}

On determining the heat load, the amount of exergy required for the heating is determined. In order to determine the exergy required, the quality factor of the room air is to be estimated. Since heat energy is a form of low-grade energy, the amount of exergy present in the heat energy is determined by the quality factor which is to be estimated by means of Carnot efficiency, given as

$Y_{q, \text { room }}=1-\frac{T_{\text {amb }}}{T_{\text {room }}}$.

The amount of exergy required for satisfying the heat load demand is given as

$\dot{\varepsilon}_{\text {room }}=Y_{q, \text { room }} \cdot \dot{Q}_{\mathrm{T}}$.

The amount of exergy given by the geothermal fluid is calculated as

$\dot{\varepsilon}_{\text {geo }}=\dot{m}_{\text {geo }}\left[\left(h_{\text {geo,in }}-h_{o}\right)-T_{\text {amb }}\left(s_{\text {geo,in }}-s_{o}\right)\right]$.

The value of enthalpy and entropy of the secondary radiator fluid as a function of temperature and pressure are calculated using the relations given by Cooper and Dooley (2007).

\subsubsection{Storage system}

The amount of exergy stored in the PCM is given by Bjurstrom and Carlsson (1985):

$$
\begin{aligned}
& \varepsilon_{\text {stored }}=M_{\mathrm{pcm}} C_{\mathrm{pcm}} T_{\mathrm{amb}} \alpha\left[\left(\theta_{m}-\theta_{b}\right)-\ln \left(\frac{1+\theta_{m}}{1+\theta_{b}}\right)\right] \\
& +\omega\left(\theta_{l}-\theta_{b}\right) \frac{\theta_{m}}{1+\theta_{m}}+\sigma\left[\left(\theta_{s}-\theta_{m}\right)-\ln \left(\frac{1+\theta_{s}}{1+\theta_{m}}\right)\right] .
\end{aligned}
$$

\subsection{Exergoeconomic analysis}

The total exergy given to a system as fuel exergy is transformed into product exergy and remaining energy is lost in the form of exergy destruction and exergy loss. The increase in efficiency causes an increase in exergy output for a given input but it also causes an increase in cost that is required to improve the system. For exergoeconomic analysis, cost is assigned for every exergy flow in a system. The cost is proportional to the amount of exergy the flow contains. The product cost is defined according to the fuel cost, capital expenditure, and other operation and maintenance costs required for production or services. The general equation is given as

$\dot{C}_{\mathrm{P}}=\dot{C}_{\mathrm{F}}+\dot{Z}^{\mathrm{Cl}}+\dot{Z}^{\mathrm{OM}}$.

The equation signifies that the total cost associated with the product is the sum of the fuel cost, capital investment, 
and the other costs related to the operation and maintenance of the system that produces the product.

A general cost balance equation in terms of cost per unit exergy for an $i$ th component with heat and work interactions with the surroundings can be represented in terms of cost per unit exergy as

$$
\begin{aligned}
& \sum c_{\mathrm{out}, i} \dot{\varepsilon}_{\mathrm{out}, i}+c_{w, i} \dot{W}_{i} \\
= & \sum c_{\mathrm{in}, i} \dot{\varepsilon}_{\mathrm{in}, i}+c_{Q, i} \dot{\varepsilon}_{Q, i}+\dot{Z}_{i}^{\mathrm{Cl}}+\dot{Z}_{i}^{\mathrm{OM}} .
\end{aligned}
$$

The inlet cost in the above equation is obtained from the exit cost of the previous component. For the first component, the inlet cost is the cost at which the fuel is supplied. Hence the above equation can be solved for the unknowns.

\subsubsection{Purchase equipment cost}

For real-life applications, equipment cost can be obtained from a vendor's catalogue. Generally, it is not possible to obtain detailed cost of every component for every design condition. For such cases the literature provides some useful sources. Mathematical charts and relationships established from past experiences are available, giving cost value in terms of different parameters such as design and geometry. The simplest way of estimating product cost is using exponential law that defines the product cost as an exponential function of the size of the component. The relation is given as follows:

$I=I_{\mathrm{r}}\left(\frac{S}{S_{\mathrm{r}}}\right)^{e}$.

Such a relation is assumed to be valid for a given range of equipment size. A general sixth-tenth rule is used for any equipment by taking the value of the exponent $e$ as 0.6. Different values of reference costs and their size along with the type of component were given by Boehm (1987). Because of various economic factors, the cost always changes with time. The above relation is for finding the cost from the reference cost of the indexed year. The obtained cost is brought to the current year cost by using a conversion relation given as follows:

reference year cost $=$ original cost

$\times \frac{\text { reference year cost index }}{\text { cost index for year for which calculation was made }}$.

The cost index used in the above equation takes into consideration the inflation in the cost of material, equipment, and labour. Various cost indices are available in the literature. The current analysis uses the Marshall and Swift cost index (Marshall et al., 2009) for indexing the equipment cost. The exergoeconomic analysis requires levelized costs of the equipment. For converting investment cost into levelized costs, the capital recovery factor (CRF) calculated for the interest rate of $i \%$ with $N$ years of life and $t$ hours of annual operation is used, given by the following equation:

$\mathrm{CRF}=\left(\frac{i(1+i)^{N}}{(1+i)^{N}-1}\right)\left(\frac{1}{t \cdot 3600}\right) s^{-1}$.

The other factor to be taken into consideration while calculating component cost is the operation and maintenance cost. The analysis assumes $2 \%$ of the investment cost of each component to be the operation and maintenance cost $(\beta)$. The cost flow rate for a given $i$ th component is then calculated as

$\dot{Z}_{i}=\frac{I_{i}(\mathrm{CRF}+\beta)}{t}$.

\subsubsection{Exergy costing}

Guidelines for obtaining equations for different streams can be found in the literature (Bejan et al., 1996). The present case mainly involves the use of heat exchanging components. The balancing equations for the components used are described below.

\section{Heat exchanger}

In this system a heat exchanger is used to deliver heat coming from the geothermal inlet stream to the radiator exit stream, which is the product stream. Hence the following equations are obtained:

$\dot{C}_{\text {geo,in }}-\dot{C}_{\mathrm{HX}, \text { out }}+\dot{C}_{\mathrm{R}, \text { out }}-\dot{C}_{\mathrm{R}, \text { in }}=-\dot{Z}_{\mathrm{HX}}$.

Also, since the fuel side is that of the geothermal stream, its cost per unit exergy remains constant. The equation is given as

$\frac{\dot{C}_{\text {geo,in }}}{\dot{\varepsilon}_{\text {geo,in }}}=\frac{\dot{C}_{\mathrm{HX}, \text { out }}}{\dot{\varepsilon}_{\mathrm{HX}, \text { out }}}$.

\section{Radiator}

The cost associated with the radiator is charged to the product which is the exergy flowing out from the radiator for room heating. The equation obtained is

$\dot{C}_{\mathrm{R}, \text { in }}-\dot{C}_{\mathrm{R}, \text { out }}-\dot{C}_{\text {heating }}=-\dot{Z}_{\mathrm{R}}$.

Also, no exergy is added to the inlet stream; hence the cost per unit exergy remains the same, and the equation obtained is

$\frac{\dot{C}_{\mathrm{R}, \text { in }}}{\dot{\varepsilon}_{\mathrm{R}, \text { in }}}=\frac{\dot{C}_{\mathrm{R}, \text { out }}}{\dot{\varepsilon}_{\mathrm{R}, \text { out }}}$. 


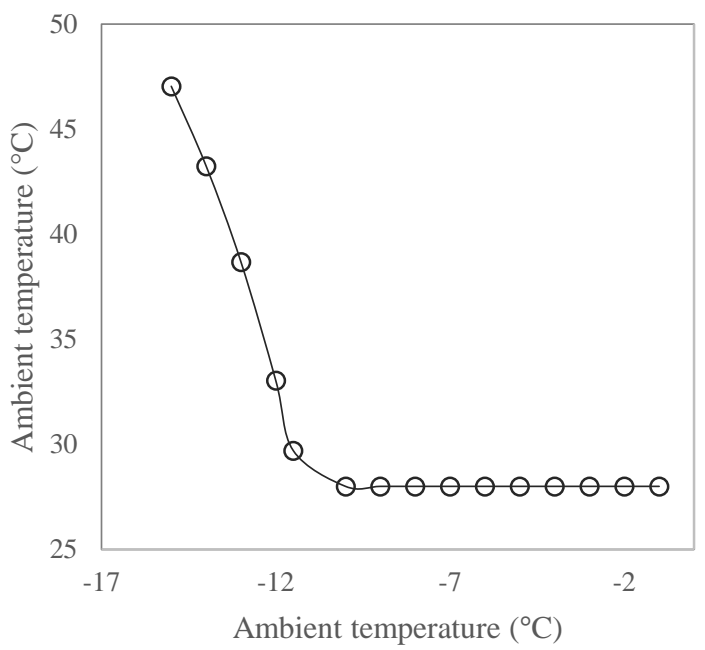

Figure 3. Variation of storage temperature with ambient temperature after an hour of operation.

\section{Storage system}

The cost associated with the storage is charged to the product which is the exergy stored in the system. The equation obtained is

$\dot{C}_{\mathrm{HX}, \text { in }}-\dot{C}_{\text {geo,out }}-\dot{C}_{\text {storage }}=-\dot{Z}_{\text {storage }}$.

Also, no exergy is added to the inlet stream; hence the cost per unit exergy remains same, and the equation obtained is

$\frac{\dot{C}_{\mathrm{HX}, \text { out }}}{\dot{\varepsilon}_{\mathrm{HX}, \text { out }}}=\frac{\dot{C}_{\text {geo,out }}}{\dot{\varepsilon}_{\text {geo,out }}}$.

The above linear equations can be solved simultaneously to obtain the unknown variables.

\section{Results and discussions}

In order to achieve an optimized heating system, a low temperature of geothermal fluid at the exit of the heat exchanger is required, signifying high heat exchange in the radiator. With the aim of improving thermodynamic efficiency, the heating system design was simulated by parallel addition of heat storage using phase change material for different ambient temperatures and for different time durations of the heat storing process in the phase change material. The design load for the radiator heating arrangement assumed was $35 \mathrm{~kW}$ at a temperature of $-15^{\circ} \mathrm{C}$. The room temperature is assumed to be $20^{\circ} \mathrm{C}$. The inlet temperature of the geothermal water was assumed to be $80^{\circ} \mathrm{C}$.

Figure 3 shows the variation of storage temperature with ambient temperature after an hour of the heat transfer process. It is found that at a lower ambient temperature, heat gained by phase change material is high enough to reach the temperature above transition quickly. This occurs due to high

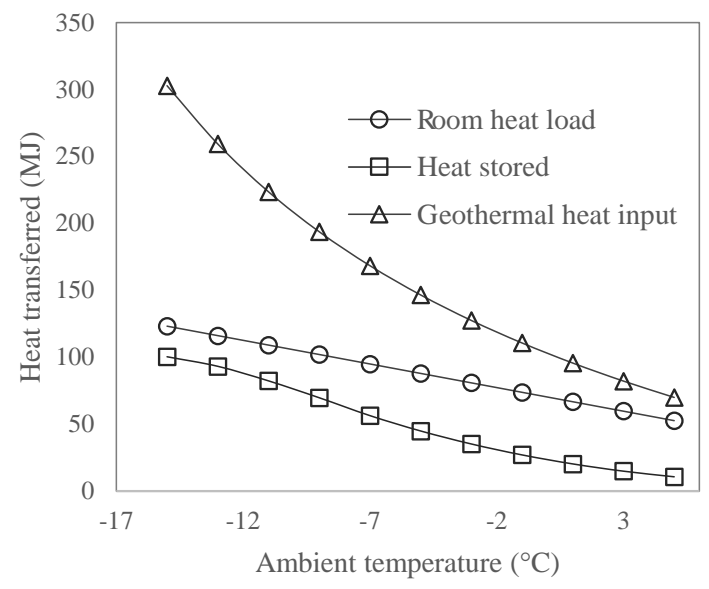

Figure 4. Variation of heat transferred with ambient temperature after an hour of operation.

temperature and mass flow rate of geothermal fluid at the storage inlet. With an increase in ambient temperature, storage inlet temperature and mass flow rate of the geothermal fluid decreases, causing less heat transfer rate between the geothermal fluid and the phase change material. This causes phase change material to still be in the transition stage after the same interval of time as that for lower temperature.

Figure 4 shows the variation of heat changes for different ambient temperatures after an hour of the heat storing process that keeps all other parameters constant. With the increase in ambient temperature, heat input from the geothermal fluid decreases. This occurs due to a low geothermal fluid exit temperature at the heat exchanger exit at the high ambient temperature. The mass flow rate of the geothermal fluid required also decreases with the increase in ambient temperature which also causes a decrease in heat input from the geothermal fluid. Room heat load shows continuous decrease as the ambient temperature increases. The amount of heat gained by phase change storage is higher at lower temperatures and decreases with an increase in ambient temperature. At a lower ambient temperature, the phase change material is above the transition stage. The amount of heat stored is higher as a high mass flow rate of geothermal fluid at a lower temperature also adds to high heat storage. The amount of heat stored at a lower ambient temperature is the summation of latent heat of material and the sensible heat stored up to the storage temperature of material at that time period. The exergy changes also show similar trends as shown in Fig. 5. Figures 4 and 5 show the significant contribution made by phase change storage in energy saved at low ambient temperatures. The graphs show that the energy and exergy stored are small in comparison to the total input, but are significant in comparison to the room heat load.

Figure 6 shows the variation of the phase change material storage temperature with time during the charging process, assuming an outside ambient temperature of $-10^{\circ} \mathrm{C}$. 


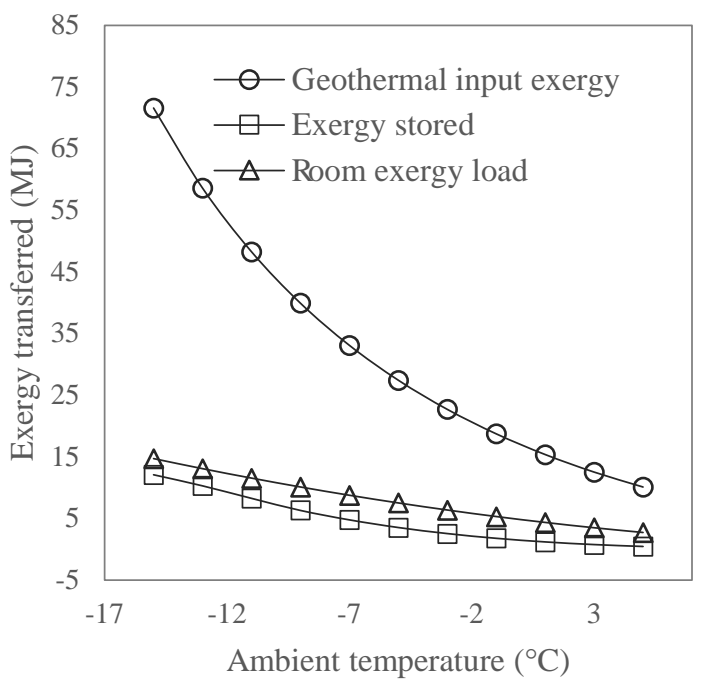

Figure 5. Variation of exergy changes with ambient temperature.

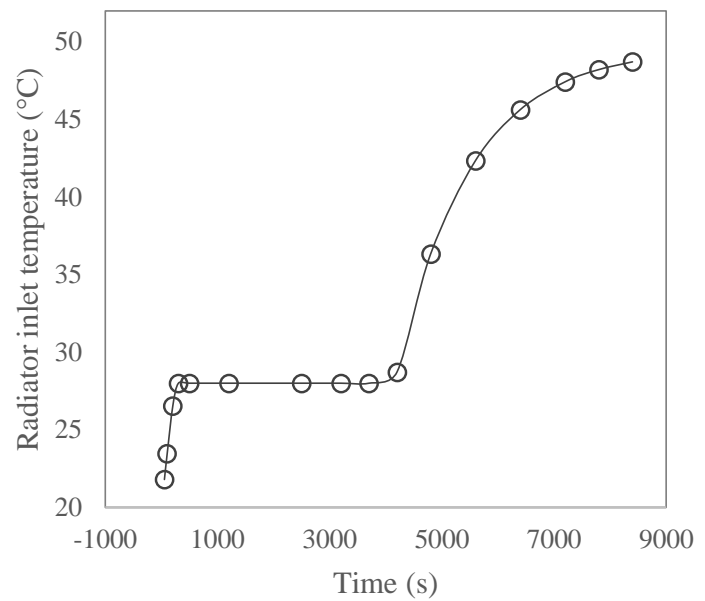

Figure 6. Variation of storage temperature with time at $-10^{\circ} \mathrm{C}$ ambient temperature.

The initial temperature of the phase change material is assumed to be equal to the room temperature. With an increase in storage time, the storage temperature increases until the transition temperature occurs. Since the temperature difference between the heat source fluid and the storage temperature is high, heat transfer is high, causing a rapid increase in temperature. On reaching the transition temperature, heat transfer occurs at constant temperature until the latent heat of the material is absorbed. After the transition phase is over, storage temperature starts increasing again. The initial phase of the storage temperature shows a high rate of increasing temperature and then starts decreasing as the storage temperature becomes closer to the heat transfer fluid inlet temperature.

Figure 7 shows the variation of total heat given by the geothermal heat source fluid, room heat load, and stored heat

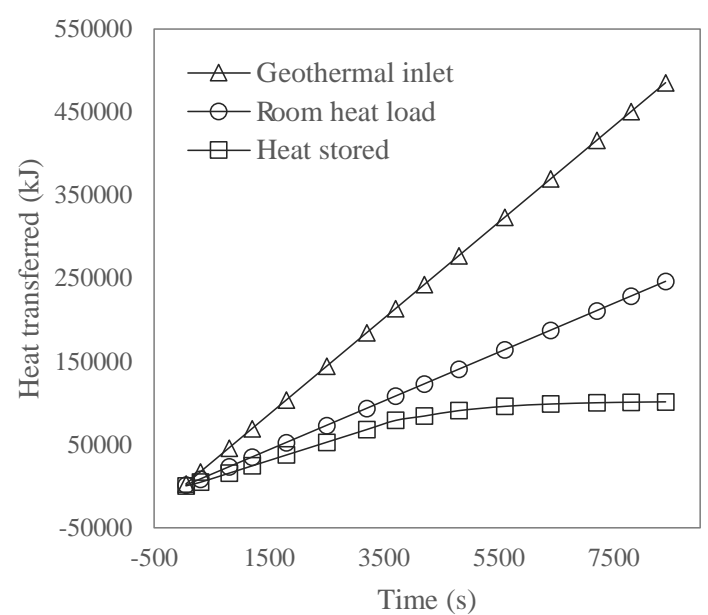

Figure 7. Variation of total heat transferred with time at $-10^{\circ} \mathrm{C}$ ambient temperature.

with time. With an increase in time duration the room heat increases constantly as the ambient temperature is fixed; hence we have a fixed heat load. Total geothermal heat input from the geothermal heat source also increases linearly since for a constant room heat load mass, the flow rate of geothermal fluid also remains constant and the inlet hot fluid temperature is also fixed. The constant increase is reflected by the constant slopes of the geothermal heat input and room heat load in Fig. 7. On the other hand the total heat stored increases constantly until the transition stage is complete and after that it decreases until the total heat stored becomes constant. The total heat stored shows a constant slope during the latent heat absorption. After that, sensible heat storage starts taking place and the rate of heat storage decreases as the storage temperature starts approaching the heat source fluid temperature. It can be seen from the graph that the room heat load requirement is much smaller than the total heat input from the geothermal fluid. The addition of the phase change storage system makes a significant heat saving comparable to the room heat load requirement. The significant amount of heat stored can be enough for satisfying the heat load requirement during the daytime when the heat load is less.

Figure 8 shows the variation of total exergy stored in phase change material with time. The initial phase of the storage process shows constant increase in exergy accumulation in the phase change storage process. This exergy accumulation process increases constantly until latent heat storage takes place. After the phase transition is over, sensible heating starts. The exergy accumulation in the phase change storage then starts decreasing as the phase change storage temperature approaches geothermal fluid inlet temperature.

Figure 9 shows the variation of fractional exergy stored as a function of fractional heat stored. The fractional exergy stored represents the ratio of rate of exergy storage to the total inlet exergy flow rate. The fractional heat stored is de- 


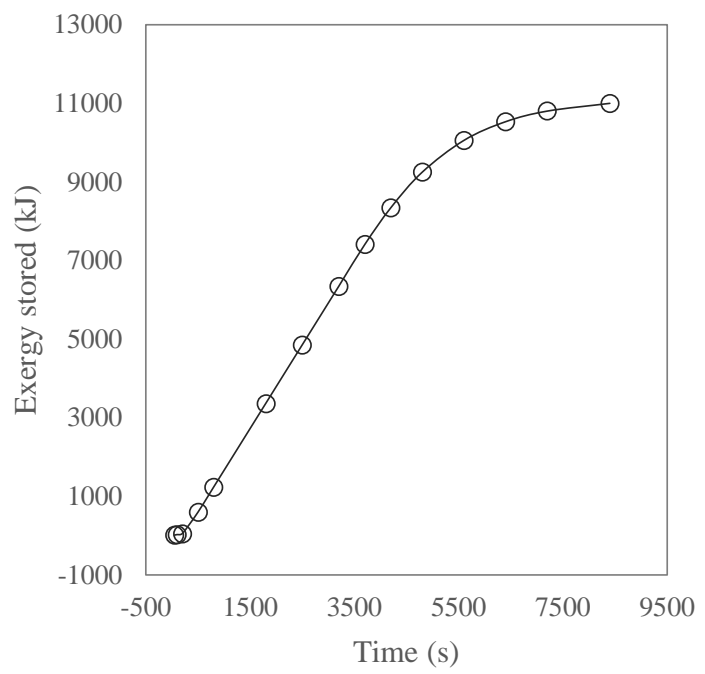

Figure 8. Variation of total exergy stored with time at $-10^{\circ} \mathrm{C}$ ambient temperature.

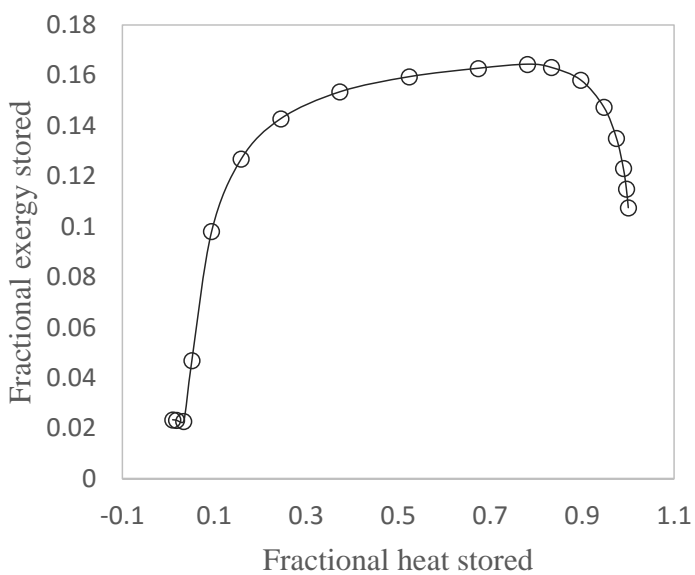

Figure 9. Variation of fractional exergy stored with fractional heat stored.

fined as the ratio of cumulative heat stored to the total heat stored. The initial and end part of the curve represents heat storage due to sensible heating and the middle constant range represents latent heat storage. It is seen from the graph that major exergy accumulation takes place only in the latent heat change process and sensible heating of phase change material does not contribute much to exergy storage. Hence it can be concluded from the graph that latent heat storage makes a greater contribution to heat storage than sensible heat does.

Figure 10 shows the variation of cost flow per unit exergy at different ambient temperatures. The inlet cost flow rate of the geothermal fluid is associated with that of well and pumping cost. Since the well cost varies from place to place, the current analysis assumes a well cost of USD 0.5 million and 0.1 million $\mathrm{kWh}^{-1}$ for the pumping cost with a total required head of $200 \mathrm{~m}$ from the pump and $7000 \mathrm{~h}$ of operation annually. The discharge from the well is assumed to be $12 \mathrm{~kg} \mathrm{~s}^{-1}$.

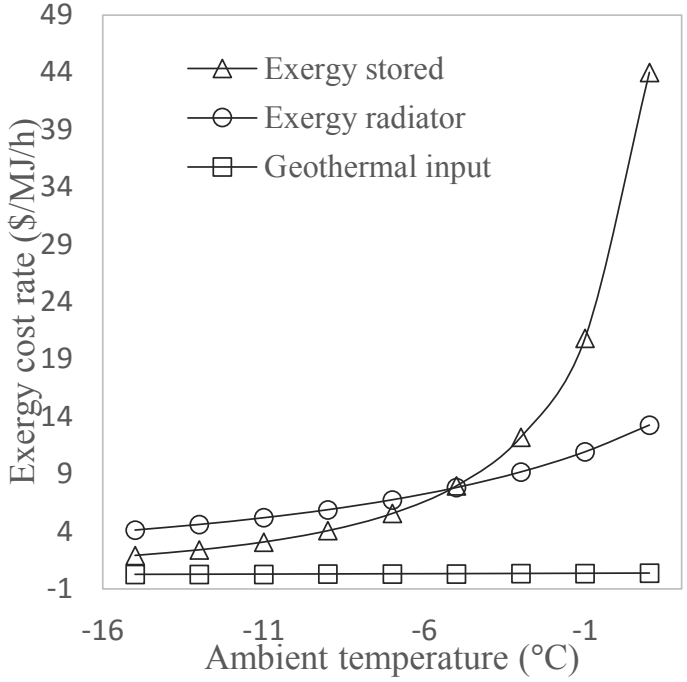

Figure 10. Variation of exergy cost flow rate per unit exergy with ambient temperature.

The exergy flow rate from a geothermal fluid depends upon the ambient temperature. With an increase in ambient temperature, exergy per unit mass flow rate of geothermal fluid decreases as the reference temperature increases. Also, the increase in ambient temperature causes a decrease in mass flow rate through the well as heat load decreases. These two factors cause cost flow rate of the geothermal fluid to increase with ambient temperature. Cost flow rate of exergy supplied by the radiator to the room increases with ambient temperature. As the ambient temperature increases, heat load required decreases, causing the required exergy flow rate to decrease. The decrease in exergy flow rate does not affect the purchase cost associated with the heat exchanger and radiator since the size of the equipment depends upon the design conditions for the minimum ambient temperature. A similar variation is found for the cost flow rate of exergy stored in the phase change storage system. The increase is found to be greater at a higher ambient temperature. This occurs because as the ambient temperature increases, the heat exchanger exit temperature and the mass flow rate decreases, causing a lower exergy flow rate at the heat exchanger exit. The decrease in exergy flow rate causes an increase in cost flow per unit exergy as the purchasing cost remains the same as that for minimum ambient design conditions. An important observation as noted from the graph is the difference in cost flow rates of the radiator heating and the stored exergy. It can be seen from the graph that the cost flow rate of stored exergy is lower than the radiator heating at a lower ambient temperature. Since with the increase in ambient temperature, the cost flow rate of radiator heating increases, the amount of exergy stored at lower temperature with a low cost flow rate can be used at higher temperatures, resulting in cost savings. 
Table 1. Exergy and cost flow rates at $-5^{\circ} \mathrm{C}$ ambient temperature.

\begin{tabular}{lrr}
\hline State point & $\begin{array}{r}\text { Exergy flow } \\
\text { rate }(\mathrm{kW})\end{array}$ & $\begin{array}{r}\text { Cost per unit exergy } \\
(\mathrm{USD} \mathrm{MJ}\end{array}$ \\
\hline Geothermal inlet & 7.61 & 0.32 \\
Storage inlet & 0.32 & 0.32 \\
Storage exit & 1.6 & 0.32 \\
Radiator inlet & 6.04 & 0.69 \\
Radiator exit & 1.77 & 0.69 \\
Room heating & 2.08 & 7.83 \\
Storage & 0.69 & 7.98 \\
\hline
\end{tabular}

Table 1 shows the exergy and cost flow rate per unit exergy at different state points in the combined heating and storing system at $-5^{\circ} \mathrm{C}$ ambient temperature. The values of cost flow rates per unit exergy show that each system, including geothermal wells and pumping, the heating system, and the heat storage system, makes a significant contribution to the overall product cost flow rate, that is, the cost of room heating and storing exergy. Also, the low value of exergy storage cost in comparison to room heating using a radiator system at lower ambient temperatures has the advantage of storing exergy at low ambient temperatures.

\section{Conclusion}

Thermodynamic and exergoeconomic analysis of space heating was performed using geothermal energy. The cost involved with drilling and pumping also contributes to the total cost for space heating using geothermal energy. The cost becomes significant when the flow rate requirement is high due to a high heat load requirement. The variation of the heating system efficiency with ambient temperature was studied. The heating system efficiency was found to be low at a lower ambient temperature; hence thermal losses become significant at lower temperatures.
A parallel combination of phase change storage system with heating system was studied. Heat supplied to the storage system was provided from the exit of the heat exchanger. Thermodynamic studies of the heat storage process at different time and ambient temperatures were conducted. Higher heat storage was observed at low ambient temperatures. The rate of exergy storage during the latent heat transition period was found to be larger than sensible heat storage. A sufficient amount of exergy was stored during the charging period at low temperatures which could be used to fulfill the daytime heat load requirement.

An exergoeconomic analysis of the combined heating and storage system was carried out. At a low ambient temperature, the cost flow rate of the exergy storage was found to be lower than the radiator heating cost flow rate. For the assumed value of investment cost flow rates, the heat storage using phase change material was found to be more economical than radiator heating to temperatures of $-5^{\circ} \mathrm{C}$. The cost flow rate of radiator heating exergy increases with increases in ambient temperature. The use of exergy storage at low ambient temperatures for heating at higher ambient temperatures makes a significant contribution to cost savings. Future work shall focus on the optimization of design parameters which influence the thermodynamic and thermoeconomic performance of the system. 
Appendix A

Table A1. Nomenclature.

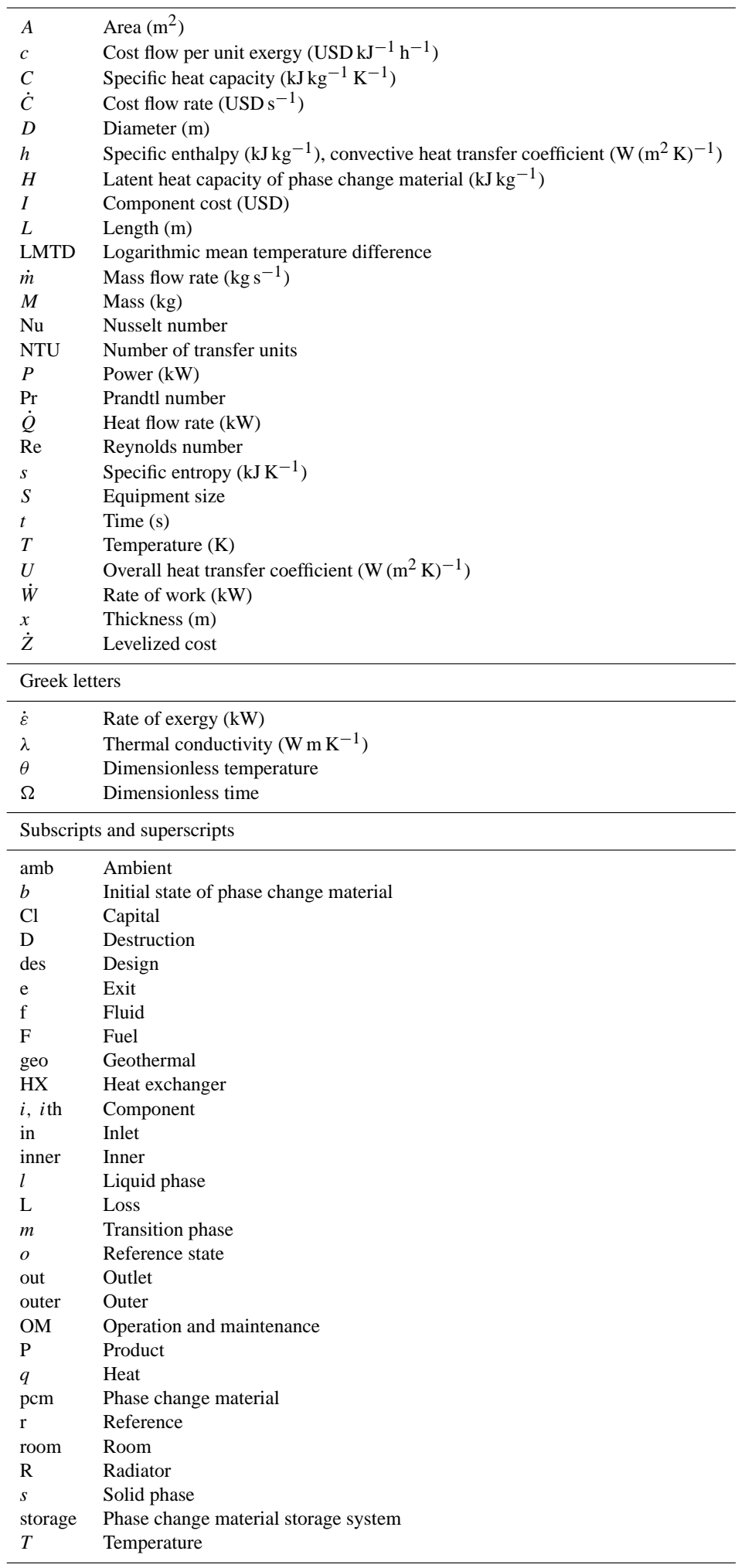


Acknowledgements. The authors would like to thank the anonymous reviewers for their valuable comments and suggestions that greatly improved the paper. A special acknowledgment goes to the GtES chief-executive editor, Horst Rüter, and the United Nations University Geothermal Training Programme in Iceland for their support.

Edited by: H. Rüter

Reviewed by: two anonymous referees

\section{References}

Abhat, A.: Low temperature latent heat thermal energy storage: heat storage materials, Solar Energy, 30, 313-332, 1983.

Adebiyi, G. A. and Russell, L. D.: Second law analysis of phasechange thermal energy storage systems, Proceedings ASME, WA-HTD-80, Boston, MA, 9-20, 1987.

Annex 37: Low Exergy Systems for Heating and Cooling of Buildings, IEA Energy Conservation in Buildings and Community Systems, Technical Presentations, Zurich, Switzerland, 12 July 2000, available at: http://virtual.vtt.fi/virtual/proj6/ annex37/, 2000.

Bejan, A.: Entropy generation minimization: The new thermodynamics of finite size devices and finite time processes, J. Applied Physics, 79, 1191-1218, 1996.

Bejan, A., Tsatsaronis, G., and Moran, M.: Thermal Design and optimization, John Wiley \& Sons, New York, 542 pp., 1996.

Bjurstrom, H. and Carlsson, B.: An exergy analysis of sensible and latent heat storage, J. Heat Recov. Sys., 5, 233-250, 1985.

Boehm, R. F.: Design and Analysis of thermal systems, John Wiley and Sons, New York, 259 pp., 1987.

Cooper, J. R. and Dooley, R. B.: Revised Release on the IAPWS Industrial Formulation 1997 for the Thermodynamic Properties of Water and Steam, Lucerne, Switzerland, 2007.

DIN 4703-1:1999-12: Raumheizkörper - Teil 3: Umrechnung der Norm-Wärmeleistung, Beuth Verlag, Berlin, Germany, 1977 (in German).

El-Dessouky, H. and Al-Juwayhel, F.: Effectiveness of a thermal energy storage system using phase change materials, Energ. Convers. Manage., 38, 601-617, 1997.

Farid, M. M., Khudhair, A. M., Razack, S. A. K., and Al-Hallaj, S.: A review on phase change energy storage: materials and applications, Energ. Convers. Manage., 45, 1597-1615, 2004.
Hepbasli, A.: A review on energetic, exergetic and exergoeconomic aspects of geothermal district heating systems (GDHSs), Energ. Convers. Manage., 51, 2041-2061, 2010.

Incropera, F. P., Dewitt, D. P., Bergman, T. L., Lavine, A. S., and Middleman, S.: Fundamentals of Heat and Mass Transfer: An Introduction to Mass and Heat Transfer, 6th Edn., John Wiley and Sons Inc., 1720 pp., 2007.

Jingyana, X., Juna, Z., and Na, Q.: Exergetic cost analysis of a space heating system, Energ. Buildings, 42, 1987-1994, 2010.

Karlsson, T. and Ragnarsson, A.: Use of very low temperature geothermal water in radiator heating system, Proceedings of the World Geothermal Congress, Florence, Italy, 2193-2198, 18-31 May 1995.

Keçebaş, A.: Performance and thermo-economic assessments of geothermal district heating system: a case study in Afyon, Turkey, Renew. Energ., 36, 77-83, 2011.

Keçebaş, A.: Effect of reference state on the exergoeconomic evaluation of geothermal district heating systems, Renew. Sustain. Energ. Rev., 25, 462-469, 2013.

Marshall, R. J., Lozowski, D., Ondrey, G., Torzewski, K.. and Shelley, S. A. (Eds.): Marshall and Swift cost index, Chem. Eng. Mag., 64 pp., 2009.

Meester, B. D., Dewulf, J., Verbeke, S., Janssens, A. and Langenhove, H. V.: Exergetic life cycle assessment (ELCA) for resource consumption evaluation in the built environment, Build Environment, 44, 11-17, 2009.

Oktay, Z. and Dincer, I.: Exergoeconomic analysis of the Gonen geothermal district heating system for buildings, Energ. Buildings, 41, 154-163, 2009.

Saito, M. and Shukuya, M.: The human body consumes exergy for thermal comfort, LowEx News, 2, 6-7, 2001.

Shukuya, M. and Komuro, D.: Exergy-entropy process of passive solar heating and global environmental systems, Sol. Energ., 58, 25-32, 1996.

Yanadori, M. and Masuda, T.: Heat Transfer Study on a Heat Storage Container with Phase Change Materials: Part 2, Sol. Energ., 42, 27-34, 1989.

Yildiz, A. and Gungör, A.: Energy and exergy analyses of space heating in buildings, Appl. Energ., 86, 1939-1948, 2009. 